\title{
Experiências Sensíveis entre Literatura e Produção de Vídeo Estudantil
}

\author{
Experiencias Sensibles entre Literatura y Producción de Vídeo \\ Estudiantil \\ Sensitive experiences between literature and student video production
}

Camila Dalcin ${ }^{1}$

\begin{abstract}
Resumo
Através deste trabalho pretendo compartilhar vivências pedagógicas vivenciadas nas aulas de Língua Portuguesa e Literatura Brasileira. Apostando no potencial transformador da ficção, escolhi o conto Os anões, do livro homônimo de Veronica Stigger, para despertar experiências sensíveis através das multilinguagens, como a produção de vídeo estudantil. A dinâmica se dá a partir da leitura do conto que funciona como gatilho questionador de valores normatizados socialmente e, por conseguinte, refletir sobre um conceito tão caro à contemporaneidade: empatia. Dada essa reflexão de sentidos os educandos criaram expressões textuais que exploram criticamente, a partir da linguagem audiovisual, conceitos como liberdade, preconceito, medo, resistência, entre tantos possíveis. Nesta prática buscamos o protagonismo do educando, que ocupa uma posição autônoma no processo, sendo o ator principal no planejamento, na ação, na avaliação e na apropriação dos resultados do trabalho que realiza. A prática tem como propósito explorar diferentes narratividades do cotidiano, despertando olhares sensíveis sobre o outro, sobre o mundo que nos cerca.

Palavras-chave: narratividades; audiovisual; educação; autonomia
\end{abstract}

\section{Resumen}

El presente trabajo pretende compartir experiencias educativas vividas en clases de portugués y literatura brasileña, centrándose en el potencial transformador de la ficción, eligió el cuento Os anões, el libro del mismo nombre, de Verónica Stigger para despertar experiencias sensoriales a través de la lenguajem da producción de vídeo estudiantil. La dinámica se da a partir de la lectura del cuento que funciona como gatillo cuestionador de valores normatizados socialmente $\mathrm{y}$, por consiguiente, reflexionar sobre un concepto tan caro a la contemporaneidad: empatía. Dada esta reflexión de sentidos, los educandos crean expresiones textuales que explotan críticamente, a partir del lenguaje audiovisual, conceptos como libertad, prejuicio, miedo, resistencia, entre tantos posibles. Siempre buscando el protagonismo del educando, que ocupa una posición autónoma en el proceso; siendo el actor principal en la planificación, la acción, la evaluación y la apropiación de los resultados del trabajo que realiza. La práctica tiene como propósito explorar diferentes narratividades de lo cotidiano, despertando miradas sensibles sobre el otro, sobre el mundo que nos rodea.

Palabras claves: narratividades; audiovisual; la educación; autonomía

\begin{abstract}
With this work I intend to share pedagogical experiences that took place in Portuguese Language and Brazilian Literature classes. Betting in the transformative potential of fiction, I have choosen the tale Os anões, from the homonymous book by Veronica Stigger, to encourage sensitive experiences through multilinguals, through student video production. The dynamics is based on the reading of the tale that functions as a questioning trigger of socially normalized values and, therefore, reflect on a concept so dear to contemporaneity: empathy. Given this reflection of meanings the students created textual expressions that explore critically, from the audiovisual language, concepts such as freedom, prejudice, fear, resistance, among many others. In this practice wee seeked for the protagonism of the student, who occupies an autonomous position in the process; being the main actor in the planning, action, evaluation and appropriation of the results of the work he performs. The purpose of the
\end{abstract}

\footnotetext{
${ }^{1}$ Mestre em Estudos Literários pela UFSM; professora-formadora na Especialização em Ensino de Filosofia EAD UFPEL; Pelotas, Rio Grande do Sul, Brasil; camiladalc@gmail.com
} 
practice is to explore different narratives of daily life, arousing sensitive views about the other, about the world around us.

Keywords: narratives; audio-visual; education; autonomy

\section{Introdução}

Apesar dos avanços tecnológicos e da presença acentuada deles na realidade de muitos educandos, o currículo escolar ainda está preso aos meios tradicionais de ensino. Por outro lado, os alunos vivenciam um mundo em que decodificar uma imagem é tão importante quanto decodificar as letras do alfabeto. A escola vive a dicotomia entre a escrita que as políticas públicas cobram e a realidade que os alunos vivem em relação à utilização da tecnologia.

Trata-se de um ambiente de estímulos tecnológicos em que os jovens estão imersos cotidianamente, infiltrando-se em todos os setores da vida, influenciando, tanto no comportamento imediato, quanto nos valores culturais, modificando significativamente a sociedade e seus modos de viver e agir. Fotografar e realizar vídeos, se tornou algo comum no dia a dia e para isso contam com o auxílio de aparelhos como: celular, máquina fotográfica e tablets cada vez mais sofisticados. Os alunos se mobilizam comunicativamente recorrendo à tecnologia para produzir fotos e vídeos fora do espaço escolar, mas e dentro da escola, como essa ação funciona? Como são criados os vídeos estudantis?

Nessa transformação pela qual passa o processo de ensino-aprendizagem, é o aluno o ator principal dessa mudança, rompendo com a passividade que lhe foi atribuída pela escola tradicional. Nesse contexto, a produção de vídeo no espaço escolar pode promover ações que busquem o protagonismo juvenil.

A partir da realidade latente de produção de vídeo estudantil, busquei pensar o ensino de literatura, entrelaçando os efeitos catárticos da literatura com a realidade semiótica do educando, representada pelo audiovisual. Tentando com isso aproximar e discutir questões que considero fundamentais à formação crítica dos estudantes, como: autonomia, empatia, protagonismo e criticidade.

\section{Ler: um experimento sensível}

A contemporaneidade é discutida ao longo do processo formador do educando e um dos territórios capazes de olhar sobre esse contemporâneo é a literatura e com ela os mais diferentes mundos possíveis que são criados. Por acreditar no potencial transformador da ficção, escolhi, como professora de Língua Portuguesa e Literatura Brasileira, o conto Os 
anões, do livro homônimo, de Veronica Stigger, para trabalhar em sala de aula dos cursos Técnicos do Instituto Federal Sul-rio-grandense Campus Pelotas.

É importante esclarecer que o Instituto atende diferentes modalidades educacionais, uma delas é o curso Técnico Integrado, no qual os estudantes cursam as disciplinas do Ensino Médio, mais as específicas dos técnicos, ao longo de oito semestres. Hoje são oferecidos os cursos: Comunicação Visual, Edificações, Design de Interiores, Química, Eletrônica, Eletrotécnica e Eletromecânica. Atendo turmas de todos os cursos, que estão em diferentes adiantamentos (semestres), com exceção do último citado. O trabalho nos mais diversos cursos me dá um campo de ação bastante heterogêneo, o que torna ainda mais rica a experiência pedagógica que passo a relatar, que foi experienciada em cinco das dez turmas que atuo.

A escolha do conto Os anões se deu, sobretudo, pelo impacto da sua narrativa. Não passando de duas páginas, o conto relata a história de um casal de anões que vai à confeitaria e é acusado por outros frequentadores de furarem a fila. $\mathrm{O}$ que gera cenas de extrema violência: os anões são espancados até a morte pelos personagens que esperam na fila e justificam o ato por sentirem que seus direitos foram lesados. Um elemento muito importe da perspectiva narrativa é o fato de estar em primeira pessoa. Uma personagem feminina que está esperando na fila é quem nos conta essa história e tenta, desde o inicio da narrativa, nos convencer da razão pelo qual os anões mereceram serem mortos.

O enredo por si só já causa um estranhamento nos leitores, pela violência gratuita na qual é embasado. Além disso flerta com elementos do fantástico e do absurdo, por exemplo, quando uma gosma verde sai da cabeça dos anões ou quando uma massa vermelha disforme é varrida pela atendente quando a barbárie acaba, que levam a distanciarmos o argumento do conto da realidade. Entretanto, podemos analisar essas escolhas estéticas como fator poético da autora para nos fazer refletir sobre o mundo que nos cerca. Como se através do impacto do absurdo nos remetesse a tantas violências cotidianas.

No primeiro momento, a reação dos educandos é de que o conto está distanciado da realidade, que os fatos narrados não condizem com o mundo real. Entretanto, quando em sala de aula, pensamos nele em termos metafóricos, os estudantes trazem questões como: o que a figura dos anões simboliza no nicho social da confeitaria? Como essa diferença é tratada? Por que não temos a perspectiva dos próprios anões relatada?

Quando entendemos que os anões podem simbolizar o diferente, o que não se encaixa na norma, começamos a perceber como essa diferença é tratada por pessoas "comuns" representados pelos que esperam na fila - e, como se buscam justificativas por esse grupo de 
culpabilizar quem não corresponde ao comportamento padrão. O que em termos estruturais explica a narradora em primeira pessoa.

Diante dessas possibilidades interpretativas, as leituras se ampliam, e no lugar do primeiro impacto, entram temas que são vivenciados pelos educandos como: preconceito, racismo, homofobia, machismo, intolerância religiosa, discurso de ódio, projetados por exemplo no ataque ao sistema de cotas raciais nas universidades públicas; assim como a violência contra transgêneros, que hoje coloca o Brasil no topo dos países que mais matam trans no mundo. Entendendo então, que em realidade normatizadas, o que foge à norma, acaba por sofrer algum tipo de violência, e será, muitas culpabilizado por isso.

\section{Narrativas Possíveis}

A partir desse deslocamento do olhar sobre o conto, buscamos então nos colocar no lugar do outro, exercitando a empatia. Em termos textuais, criando novas narrativas. A atividade que segue à leitura é a de criar uma narrativa verbal que mude a perspectiva da narração, portanto, se temos no conto original uma primeira pessoa, representada por alguém na fila, no texto criado pelos educandos, a narrativa passa a ser contada pelos anões. Além dessa premissa, pedi que o conflito fosse mantido (a discussão pela fila supostamente furada).

O processo foi transformador, os alunos se engajaram na produção textual e criaram narrativas extremamente criativas, com tom crítico, refletindo as suas capacidades de olhar para o mundo que os cerca. Os textos foram compartilhados com a turma em leituras coletivas e a partir daí criamos uma nuvem de sensações geradas pelas histórias narradas. Surgiram palavras como amor, ódio, preconceito, invisibilidade, crueldade, intolerância, angústia, medo, resistência, empoderamento, esperança, entre tantas outras.

Dois pontos são importantes aqui, o primeiro que foi possível perceber ao longo do processo de leitura que muitos autores, até então tímidos com seus textos, se desapegaram da baixa autoestima como escritores, e reconheceram suas capacidades criativas e de escrita, reverberando uma sensação de autonomia. O segundo é que as sensações geradas por essas potencias criativas serviram de gatilho para o nosso próximo processo narrativo, agora recorrendo a outros meios comunicacionais, não mais presos ao verbal, mas sim, se apropriando de outras semioses.

A proposta foi de que, coletivamente, cada grupo escolhesse uma palavra da nuvem de sensações para representar através de outras mídias, a maioria decidiu pela linguagem cinematográfica. Como resultado foram criados vídeos de dois a cinco minutos, que 
priorizaram a imagem como principal meio comunicacional e exploraram os temas das formas mais diversas.

Vou me debruçar sobre os trabalhos que desenvolveram os temas: violência e empoderamento; porque acredito serem estes vídeos os que mais simbolizam o potencial crítico dos educandos. Em todas as turmas, mais de um grupo abordou essa temática, sobretudo, a partir da violência contra a mulher - relacionamento abusivo; violência física; moral; psicológica - e a trans e homofobia. Cabe ressaltar a perspectiva sobre esses conceitos, os grupos compostos na maioria por meninas, buscaram representar as violências e como elas progridem caso não se procure ajuda. Mostraram através de imagens, de dados, da trilha sonora, os atores sociais que frequentemente sofrem com essa realidade, assim como trouxeram exemplos com possíveis caminhos de conscientização.

\section{Multiletramentos e o processo pedagógico}

Essas dinâmicas foram pautadas em ações pedagógicas que buscam o protagonismo do estudante, ou seja, o aluno ocupa uma posição de centralidade no processo de ensinoaprendizagem, trazendo à sala de aula questões importantes do mundo contemporâneo através dos códigos comunicacionais que compõe o seu cotidiano, inspirada na pedagogia das multi linguagens.

As ações de leitura e de escrita, independente do(s) código(s) com o(s) qual/quais o professor trabalha, não se limitem ao verbal - código geralmente privilegiado na escola tradicional. Para vencer o fictício, é necessário que esses códigos sejam relacionados uns com os outros de modo a encaminhar o aluno à interpretação crítica de discursos que circulam em diferentes esferas e contextos - culturais, sociais, econômicos, etc.

Deve-se levar em consideração que, hoje, as ferramentas informacionais e comunicacionais suscitadas pelo avanço tecnológico ampliaram o acesso à informação. Assim, os conhecimentos e as habilidades que caracterizam o sujeito como letrado têm sido resignificados levando-se em consideração a vasta utilização dos recursos tecnológicos e a produção e publicação de textos - verbais e não verbais - em contextos digitais (SILVA, 2014).

Essa teoria suscitou um novo olhar aos estudos dos letramentos ao colocar no centro de suas análises a crescente diversidade linguística e cultural e a multiplicidade de canais e meios - modos semióticos -, disseminados com o avanço tecnológico. Trata-se de uma proposta que problematiza a emergência de um novo paradigma para a educação dentro de um ambiente midiatizado, levando em conta a relevância do mundo das comunicações no 
contexto escolar (PIRES, 2010).

Segundo Cope e Kalantzis (2000), que estão entre os autores que inauguraram a teoria, a diversidade linguística e cultural e a multiplicidade de canais e meios são os principais motes responsáveis pelo acréscimo do prefixo multi ao termo letramento, e que dá conta das formas de letramento ligadas à "crescente multiplicidade e integração de modos de construção de significado, em que o textual está integrado ao visual, ao áudio, ao espacial e ao comportamental, etc" (p.64).

No Brasil, Rojo (2002) afirma que há uma importante adesão de professores aos princípios que norteiam esse tipo de concepção de educação, no entanto, o que se pôde verificar nas pesquisas dedicadas ao presente artigo é que ainda são incipientes estudos que problematizam a produção de vídeo estudantil como prática de multiletramento.

Por focar a multiplicidade e hibridação de linguagens e culturas convocadas pela sociedade contemporânea em processos de construção de significados assim como as implicações éticas de tais processos no mundo do trabalho, no pluralismo cívico e nos estilos de vida, a pedagogia dos multiletramentos constrói-se no imbricamento entre teoria e ato ético inscritos no existirevento, representando, portanto, uma alternativa epistemológica para um trabalho docente com as linguagens no sentido de contribuir com a construção de sujeitos capazes de transitar, compreendendo, interpretando e respondendo, a partir de posicionamentos valorados, (a)os discursos produzidos e circulantes nessa sociedade (SZUNDY; OLIVEIRA, 2014, p.199).

Daqueles que já circulam no espaço acadêmico, Almeida (2013) situou suas análises na área das Letras, ressaltando a importância da produção de vídeo na escola. Segundo a autora, trata-se de uma prática que aciona

[...] o uso pedagógico de aparatos que inexoravelmente fazem parte do cotidiano dos estudantes - computadores, celulares e games, por exemplo não pode ser observado pelo viés da criatividade de muitos professores; ao que contrário, trata-se de ferramentas tão obrigatórias quanto a caneta e o caderno e que, por isso, precisam ser considerados como itens óbvios no planejamento escolar (ALMEIDA, 2013, p. 10-11).

Entendendo então que a pedagogia do multiletramento exige e incentiva um aluno crítico, autônomo, que o uso da internet e dos celulares na escola são instrumentos e recursos para a interação, comunicação e, mais importante, para reflexão crítica desse sujeito diante da realidade que o cerca. Para o multiletramento, o aluno passa a ser sujeito de sua aprendizagem, transformando-se em criadores de sentido, como aponta Rojo no Multiletramentos na escola: 
Há dois tipos específicos e importantes de multiplicidade presentes em nossas sociedades, principalmente urbanas, na contemporaneidade: a multiplicidade cultural das populações e multiplicidade semiótica de constituição dos textos por meio dos quais ela se informa e se comunica. (ROJO; MOURA, 2012, p. 13)

Nesse tocante, além de incentivar a autonomia do aluno e o seu empoderamento crítico, a proposta de produção de audiovisual também objetivou levá-lo a acionar múltiplos letramentos, tais como: multiplicidade de linguagens, práticas de leitura, análise crítica, trabalho colaborativo, domínio de áudio, vídeo, tratamento de imagem, edição, entre outras habilidades capazes de potencializar a criatividade do educando.

\section{Considerações finais}

Acredito que educar seja um ato de afeto e responsabilidade que pressupõe, portanto, a consciência de que nossas ações são sempre de natureza ideológica e política, tendo implicações éticas na vida com quem compartilhamos os territórios educacionais. Essa consciência do fazer implicou nos caminhos que seguimos, do conto à produção audiovisual, passando pela criação textual e os desdobramentos da leitura coletiva. Entendo que o processo teve como principais motivadores a aproximação dos estudantes com a literatura e, de forma mais intensa, com o potencial crítico das multilinguagens nos espaços comunicacionais contemporâneos.

Assim, é possível pensar que os caminhos pedagógicos possibilitam que nos tornemos ainda mais sujeitos do nosso tempo, capazes de olhar critica e subjetivamente para os espaços que ocupamos. Como diz Agambem, nos tornarmos seres contemporâneos que é "antes de tudo, uma questão de coragem: porque significa ser capaz não apenas de manter fixo o olhar no escuro da época, mas também de perceber nesse escuro uma luz." (2009, p.14).

\section{Referências}

AGAMBEN, Giorgio. O que é o contemporâneo? e outros ensaios. Trad. Vinícius Nikastro Honesko. Chapecó: Argos, 2009.

ALMEIDA, Ana Cláudia Pereira de. Produção de vídeos em sala de aula: uma proposta de uso pedagógico de celulares e câmeras digitais. \#Tear: Revista de Educação Ciência e Tecnologia, Canoas, v.2, n.1, 2013. 
CAZDEN, C; COPE, B.; FAIRCLOUGH, N.; GEE, J.P.; et al. (New London Group) (1996). A pedagogy of multiliteracies: Designing social futures. In: COPE, B.; KALANTZIS, M. (Eds.). Multiliteracies: Literacy learning and the design of social futures. London: Routldge, 2000 .

FREIRE, Paulo. Pedagogia da autonomia. Saberes necessários à prática educativa. 7. ed. São Paulo: Paz e Terra, 1996.

GOMES, Luiz Fernando. Hipertexto no cotidiano escolar. São Paulo: Cortez, 2011.

HERECHUK, Talita R. Produção de Vídeos como Prática de multiletramento nas Aulas de Geografia das Séries Iniciais. Monografia. Curso de Especialização em Mídias na Eduacação/UFRGS. Porto Alegre, 2015.

LABRUNIE, Maria das Graças Lino; FERREIRA, Giselle Martins dos Santos. O vídeo na escola: uma revisão de literatura. Revista Educação e Cultura Contemporânea, Rio de Janeiro, pg. v. 15, n. 3, pg 417- 436. 2018.

LOPES, Eloisa Assunção; BIZERRIL, Marcelo Ximenes. "Imagina, eu me vi na televisão da minha sala!’ A produção audiovisual e o empoderamento dos sujeitos do campo. Revista Educação e Cultura Contemporânea, Rio de Janeiro pg 64-91. v. 15, n. 40, pg 64-91. 2018.

ROJO, Roxane; MOURA, Eduardo. Multiletramentos na escola. São Paulo: Parábola Editorial, 2011.

SETTON, M.G.J. Cinema: instrumento reflexivo e pedagógico. In: A cultura da mídia na escola: ensaios sobre cinema e educação. São Paulo: Annablume: USP, 2004. p.67-79.

SOARES, M. Novas Práticas de Leitura e Escrita: Letramento na Cibercultura. Educ. Soc. Campinas, v. 23, n. 81, p. 143-160, dez. 2002. Disponível em <http://www.scielo.br/pdf/es/v23n81/13935> Acesso em: 02 out.2018.

STIGGER, Veronica. Os Anões. São Paulo: Cosac Naify, 2007

SZUNDY, P. ; OLIVEIRA, MARIA BERNADETE FERNANDES DE. Práticas de multiletramentos na escola: por uma educação responsiva à contemporaneidade. Bakhtiniana: Revista de Estudos do Discurso, v. 9, p. 184-205, 2014.

ROJO, Roxane. Letramentos múltiplos, escola e inclusão social, São Paulo: Parábola editorial, 2009

; MOURA, Eduardo. Multiletramentos na escola . São Paulo: Parábola editorial, 2012 